\title{
The need for race-specific reference equations for pulmonary diffusing capacity for nitric oxide
}

\author{
Gerald Stanley Zavorsky ${ }^{*}$, Ahmad Saleh Almamary², Mobarak Khalid Alqahtani ${ }^{3}$, Shi Huh Samuel Shan ${ }^{4}$ and \\ Douglas Shawn Gardenhire ${ }^{4}$
}

\begin{abstract}
Background: Few reference equations exist for healthy adults of various races for pulmonary diffusing capacity for nitric oxide (DLNO). The purpose of this study was to collect pilot data to demonstrate that race-specific reference equations are needed for DLNO.

Methods: African Americans (blacks) were chosen as the comparative racial group. In 2016, a total of 59 healthy black subjects (27 males and 32 females) were recruited to perform a full battery of pulmonary function tests. In the development of DLNO reference equations, a white reference sample (randomly drawn from a population) matched to the black sample for sex, age, and height was used. Multiple linear regression equations for DLNO, alveolar volume (VA), and pulmonary diffusing capacity for carbon monoxide (DLCO) using a 5-6 s breath-hold were developed.

Results: Our models demonstrated that sex, age ${ }^{2}$, race, and height explained $71 \%$ of the variance in DLNO and DLCO, with race accounting for approximately $5-10 \%$ of the total variance. After normalizing for sex, age ${ }^{2}$, and height, blacks had a 12.4 and $3.9 \mathrm{~mL} / \mathrm{min} / \mathrm{mmHg}$ lower DLNO and DLCO, respectively, compared to whites. The lower diffusing capacity values in blacks are due, in part, to their $0.6 \mathrm{~L}$ lower VA (controlling for sex and height).

Conclusion: The results of this pilot data reveal small but important and statistically significant racial differences in DLNO and DLCO in adults. Future reference equations should account for racial differences. If these differences are not accounted for, then the risk of falsely diagnosing lung disease increase in blacks when using reference equations for whites.
\end{abstract}

Keywords: Ethnicity, Prediction equations, Lung function, False positives, Carbon monoxide

\section{Introduction}

Pulmonary function tests (PFTs) are essential tools for modern clinical respiratory function assessment. They are used in the evaluation of patients with respiratory symptoms and for guiding the management of diagnosed lung disease. Many patients get misdiagnosed and are

\footnotetext{
*Correspondence: gszavorsky@ucdavis.edu; gerryzavorsky@gmail.com 1 Pulmonary Services Department, University of California, Davis, Medical Center, 2315 Stockton Boulevard, Room 5703, Sacramento, CA 95817. USA

Full list of author information is available at the end of the article
}

improperly treated without the guidance of PFTs. One such PFT, pulmonary diffusing capacity for carbon monoxide (DLCO), is a single-breath technique using a 10-s breath-hold maneuver that was clinically established in 1957 [1]. Since 1957, the single-breath DLCO test has become the clinical standard to assess gas transfer through the lung. Prediction equations for DLCO were developed to decipher normal from abnormal gas transfer through the lung. These equations have been created for adults [2-8] and children [9-11], with a wide range of racial backgrounds [11-20]. 
While carbon monoxide ( $\mathrm{CO}$ ) has been the transfer gas of choice for the measurement of diffusing capacity, the use of nitric oxide (NO) as a potential alternative originated much later by separate and independent research teams [21]. The first two abstracts on DLNO originated from the United Kingdom in the 1980s [22, 23]. These abstracts resulted in the first publications of DLNO [24, 25].

There is evidence to suggest that NO could be a better transfer gas compared to $\mathrm{CO}$, or at least, used alongside CO [26]. The chief barrier to CO uptake $(\sim 70-80 \%)$ resides within the red cell (i.e. red cell resistance) while $\sim 25 \%$ is located in the alveolar membrane (See Fig. 1 elsewhere [27]). In contrast, the main barrier for NO uptake resides between the alveolar and red blood cell membranes $(\sim 60 \%)$ (i.e. membrane resistance) [28]. This advantage gives DLNO a better representation of gas transfer through the alveolar-capillary membrane compared to DLCO. Unlike DLCO, DLNO is relatively unaffected by changes in hemoglobin concentration [29], carboxyhemoglobin concentration [30], alveolar oxygen pressure $\left(\mathrm{P}_{\mathrm{A}} \mathrm{O}_{2}\right)$, or inspired oxygen concentration [31, 32]. Furthermore, DLNO is more affected by lung volume compared to DLCO, which makes the KNO (mathematically, DLNO divided by alveolar volume) a better measure than KCO (mathematically, DLCO divided by alveolar volume) in those with restrictive lung disease [33]. Finally, the sensitivity in detecting cardiopulmonary disease may be improved using DLNO compared to DLCO [26]. These examples demonstrate there is evidence that a DLNO test can be technically and physiologically superior to a DLCO test [26].

Few prediction equations exist for single-breath DLNO in adults [34-38] and children [39-41] (see Additional file 1: Table S1). In addition to measurements of DLNO, DLCO prediction equations have also been developed (Additional file 1: Table S2). In 2017, a European Respiratory Society Task Force (ERS) published reference equations for DLNO [27] based on combined data from three studies evaluating nearly 500 white subjects [34-36]. However, no prediction equations for DLNO have been developed in the African-American population (herein known as the black population).

Ethnic/racial differences exist in certain aspects of lung function. For example, $15 \%$ of the variability in vital capacity is accounted for by race/ethnicity [42]. Vital capacity (i.e., lung volume) is about $15 \%$ lower in blacks compared to age, height, and sex-matched whites [13, 43]. Moreover, the DLCO is also lower in blacks compared to matched whites $[13,19]$. Specifically, DLCO is lower by $2(\sim 6 \%) \mathrm{mL} / \mathrm{min} / \mathrm{mmHg}$ in black, age and height-matched males compared to matched white males [19]. DLCO is also lower by $\sim 5$ $(\sim 15 \%) \mathrm{mL} / \mathrm{min} / \mathrm{mmHg}$ lower in black, age and height matched females compared to matched white females [19]. The difference in DLCO between blacks and whites stems from differences in alveolar volume and hemoglobin concentration as there is a $\sim 6 \%$ larger hemoglobin concentration in whites compared to blacks $[19,44]$. Although DLNO is minimally affected by hemoglobin concentration [29], the development of DLNO prediction equations for blacks is justified given the differences in lung volumes between the two different ethnic/racial groups. One study suggested that blacks originating and living Sub-Sarahan Africa have lower DLNO values compared to whites [45].

Racial differences in lung function could result in significant public health consequences if improper reference equations are used. The use of incorrect reference equations could result in the overdiagnosis of lung disease in the black population. Misdiagnosis of lung disease could result in increased patient stress and inadvertent use health care resources, resulting in a higher cost and potential harm forpatients with a false positive diagnosis. We therefore sought to demonstrate that reference equations are specifically needed for DLNO in the adult black population in the United States by sampling a black university population in Atlanta, GA. To date, there are no reference equations developed for DLNO in the African American population. As such, this study's primary aim was to determine if racial differences exist for DLNO. Pulmonary diffusing capacity in the black population was compared against sex, age, and height-matched white adults used in the 2017 ERS Technical Standards document for DLNO [27]. Moreover, since breath-hold time can alter DLCO, alveolar volume (VA), and logarithmic change in $\mathrm{CO}$ concentration per unit time and unit pressure (KCO) [46], a secondary aim was to evaluate $10 \mathrm{~s}$ and $5 \mathrm{~s}$ breath-hold times on those variables as secondary outcomes in the black population.

\section{Methodology}

Healthy black male and female non-smoking adults from Georgia State University (GSU) were recruited to participate in one testing session involving the measurement of various lung parameters, including DLNO and DLCO. Subjects were selected based on responses to a flyer that was posted around campus. This was a descriptive observational study performed in conjunction with another study examining the six-minute walk test in this same ethnic/racial group. The study was approved by the Georgia State University ethics board (IRB \#H16120, Reference \# 335,588). Informed consent was obtained prior to study participation. The inclusion and exclusion criteria were as follows: 


\section{Inclusion criteria}

- A representative sample of the university African American population, who are non-smoking and non-pregnant

- Individuals $\geq 18$ years of age, with a body mass index (BMI) ranging from 17.0 to $34.9 \mathrm{~kg} / \mathrm{m}^{2}$. Nonsmoking was defined as never smoked or quit smoking $>6$ months previously.

- Subjects did not have cardiopulmonary disease or signs/symptoms suggestive of cardiopulmonary disease [47].

\section{Exclusion criteria}

- Those that did not fit the inclusion criteria above, and:

- Those that have chest or abdominal pain or any cause, oral or facial pain exacerbated by a mouthpiece, stress incontinence, dementia, or in a state of confusion [48].

\section{Procedures}

Subjects signed an informed consent form to participate in the study. Procedures lasted approximately $1.75 \mathrm{~h}$ in total per subject. Subjects filled out a questionnaire assessing demographic data including date of birth, sex, a physical activity readiness questionnaire (PAR-Q), and a health questionnaire. Height, weight, waist, and hip circumference were measured before the pulmonary function tests. Heart rate was measured via a POLAR A300 heart rate monitor (Polar Electro Oy, Kempele, Finland) during the PFTs. Average heart rate was recorded during these PFTs (i.e., 20-30 min) and used for data analyses.

Pulmonary function tests were performed in half of the subjects the following order: (a) slow vital capacity (SVC), (b) Spirometry, (c) $5 \mathrm{~s}$ breath-hold NO-CO double diffusion measurement $\left(\mathrm{DLNO}_{5 \mathrm{~s}}, \mathrm{DLCO}_{5 \mathrm{~s}}\right)$, (d) total lung capacity (TLC), and (e) DLCO (10 s breath-hold, $\left.\mathrm{DLCO}_{10 \mathrm{~s}}\right)$. In the other half, the order of (c) and (e) were reversed. As such, the first participant that was scheduled to come to the lab for testing performed tests a-e in sequence. Then the next subject that was scheduled for testing completed tests $a, b, e, d, c$ in that order. The order of testing alternated back and forth until the end of the recruitment.

The procedures, rules, and evidence of established safety for conducting these lung function tests has been previously described [49-53]. The diffusing capacity test involved subjects inspiring approximately 4-6 L of a standard diffusion gas mixture that is used for diagnostic purposes, including a small amount of $\mathrm{NO}$ (i.e., $0.3 \% \mathrm{CO}$, $21 \% \mathrm{O}_{2}, 10 \% \mathrm{He}, 40-60 \mathrm{ppm} \mathrm{NO}$, Balance $\mathrm{N}_{2}$ ). This gas mixture was inhaled once to total lung capacity, held for 5-10 s, and then and then exhaled.

The Hyp'Air lung diffusion system (Medisoft Inc., Sorinnes, Belgium) was used for the assessment of DLNO, VA, KNO, DLCO, and KCO using the $5 \mathrm{~s}$ breathhold maneuver. Nitric oxide and $\mathrm{CO}$ electrochemical cells were used to measure inhaled and exhaled NO and $\mathrm{CO}$ concentrations. Insofar as the resolution of the NO electrochemical cell is in the ppm range, $5 \mathrm{~s}$ breath-hold maneuvers were used to prevent exhaled NO from being in the ppb range. The Medisoft Body Plethysmograph (BODYBOX $5500^{\circledR}$ Series, Medisoft Inc., Sorinnes, Belgium) was used for the assessment of spirometry, TLC, DLCO (10 s breath-hold maneuver), VA (10 s breathhold maneuver), and KCO (10 s breath-hold maneuver). The best values for spirometry were reported [49], and the mean value for DLNO and DLCO was reported when the two highest DLCO values varied by not more than $3 \mathrm{~mL} / \mathrm{min} / \mathrm{mmHg}$, and the two highest DLNO values did not vary by more than $17 \mathrm{~mL} / \mathrm{min} / \mathrm{mmHg}$ [27]. For the measurement of TLC from the body box, three values for FRC that agreed within 5\% were obtained, and the mean was reported [51].

Subjects were paid $\$ 30$ for their participation. The funding for this study came from the Jerome M. Sullivan Research Fund from the American Respiratory Care Foundation.

\section{Calculation of DLNO, DLCO}

Recommended guidelines from the ATS and ERS were used to calculate $\mathrm{DLNO}_{5 \mathrm{~s}}, \mathrm{DLCO}_{5 \mathrm{~s}}$, and $\mathrm{DLCO}_{10 \mathrm{~s}}[27$, 53]. Standardized hemoglobin concentrations were used for men $(14.6 \mathrm{~g} / \mathrm{dL})$ and women $(13.4 \mathrm{~g} / \mathrm{dL})$, respectively, was used, and $\mathrm{P}_{\mathrm{A}} \mathrm{O}_{2}$ of $100 \mathrm{mmHg}$ was also used as recommended by the ERS Task Force [27].

\section{Statistical analyses}

Spirometry values (FVC, $\mathrm{FEV}_{1}, \mathrm{FEV}_{1} / \mathrm{FVC}$ ratio) were compared to predicted values for the black population [43]. Total lung capacity was compared to the predicted values for a white population [3]. The mean predicted values were compared to the mean measured values via a paired $t$-test. When developing reference equations, the number of subjects should be sufficiently large because the larger the sample, the more likely it will be to represent the population. It is known that there is a direct relationship between the correlation and the ratio of the number of independent variables (IVs) in the model $(k)$ to the number of participants in the model $(n)$, such that $(k-1) \div(n-1)$ [54]. Thus, if a study has 40 participants 
Table 1 Anthropometric characteristics

2017 ERS technical standards (white subjects)

\begin{tabular}{lcc}
\hline & 2017 ERS technical standards (white subjects) & $\begin{array}{l}\text { Current study African } \\
\text { Americans (black } \\
\text { subjects) }\end{array}$ \\
\hline Males $(n=27$ per group) & & $28.0(9.5)$ \\
Age (years) & $30.1(6.0)$ & $176(7)$ \\
Height $(\mathrm{cm})$ & $179(8)$ & $78.6(11.1)$ \\
Weight $(\mathrm{kg})$ & $76.2(10)$ & $25.3(2.9)^{*}$ \\
BMl (kg/m $\left.{ }^{2}\right)$ & $23.7(2.2)$ & $31.9(13.6)$ \\
Females $(n=32$ per group) & $31.8(8.4)$ & $163(8)$ \\
Age (years) & $166(6)$ & $68.2(13.9)^{*}$ \\
Height $(\mathrm{cm})$ & $59.8(8.4)$ & $25.7(5.3)^{*}$ \\
Weight $(\mathrm{kg})$ & $21.6(2.4)$ & \\
BMl $\left(\mathrm{kg} / \mathrm{m}^{2}\right)$ & & \\
\hline
\end{tabular}

${ }^{*} p<0.05$ between white and black subjects

and $30 \mathrm{IVs}$, the $\mathrm{R}^{2}$ would be 0.74 based on chance alone, and the results would be meaningless; therefore, it is recommended that there be at least a 10:1 participant to variable ratio to avoid this error [54]. In this case, where there are nine potential predictors for DLNO (age, age ${ }^{2}$, age $^{3}$, sex, weight, height, height ${ }^{2}$, height ${ }^{3}$, race), at least 90 subjects would be needed.

A multiple linear regression model using the forward procedure was conducted to determine which IVs (age, age ${ }^{2}$, the interaction term age $^{3}$, sex, weight, height, height $^{2}$, the interaction height ${ }^{3}$, race) were predictors of $\mathrm{DLNO}_{5 \mathrm{~s}}$ (first dependent variable), $\mathrm{DLCO}_{5 \mathrm{~s}}$ (second dependent variable), and alveolar volume (third main dependent variable). Forward selection first determined the bivariate correlations among all IVs and the dependent variable. The procedure then determined which IV is most highly correlated with the dependent variable and chose it as the first significant predictor, and it remained in the equation. The next variable entered in the analysis was the independent variable that contributed most to the dependent variable after partialling out the effects of the first independent variable. This was measured by the increase in $\mathrm{R}^{2}$ due to the second variable. Once this IV is chosen, it remained in the equation. This procedure continued until an IV stopped making contributions to the dependent variable [55]. Any predictor variable that was statistically significant $(p<0.05)$ was initially kept in the model. However, it was also important to note efficient regression equations were developed without including everything across the board. For example, if age correlated nearly as close as age.age ${ }^{2}$, age was used instead for simplicity. Since regression was very sensitive to extreme cases, outliers were removed. Any data point that demonstrated a standard deviation of the residuals $\geq 3.5$ was eliminated. Linearity was analyzed by creating a scatterplot matrix of variables. Another plot was created between the standardized residuals (y-axis) and standardized predicts ( $\mathrm{x}$-axis) to see if the values were consistently spread out, which would indicate normality and homoscedasticity. When multicollinearity was examined, the variance inflation factor (VIF) was used to see whether there was a strong association between the independent and dependent variables. All independent variables in the model had a VIF near one [56]. If any predictor had a VIF of more than five, it was removed from the model [57]. A Durbin-Watson test was performed to test if serial errors were correlated $[58,59]$. The range was $0-4$ : a value of nearly two indicates non-autocorrelation, a value close to zero indicates a positive autocorrelation, and a value close to 4 indicates a negative autocorrelation [60].

The number of male and female black subjects recruited was then matched with the exact same number of male and female white subjects, randomly selected from a sex, age, and height matched dataset used to generate reference equations for DLNO [27]. These were historical white control subjects obtained from the 2017 ERS Taskforce publication on the standardization of DLNO [27]. To examine differences in DLCO, VA and KCO between 10 and $5 \mathrm{~s}$ breath-hold maneuvers, simple linear regressions, paired $t$-tests, and Bland-Altman plots [61] were used.

A Type I probability level of 0.05 was used. The statistical software utilized was IBM SPSS Statistics Version 26.0, IBM Corporation, Chicago, IL.

\section{Results}

Sixty adult black subjects were recruited from GSU over a period of 6 months in 2016 (Table 1). One subject had missing data and was therefore removed from the analysis. The remaining fifty-nine subjects (32 females, 27 
Table 2 Multiple linear regression results for DLNO (5 s breath-hold)

\begin{tabular}{|c|c|c|c|c|c|c|c|c|}
\hline \multirow[t]{2}{*}{$N=118$} & \multicolumn{2}{|l|}{$\begin{array}{l}\text { Unstandardized } \\
\text { coefficients }\end{array}$} & \multicolumn{2}{|c|}{ Standardized coefficients } & \multicolumn{2}{|c|}{$\begin{array}{l}95 \% \text { Confidence interval for } \\
\text { beta }\end{array}$} & \multicolumn{2}{|c|}{$\begin{array}{l}\text { Collinearity } \\
\text { statistics }\end{array}$} \\
\hline & Beta & SE & Beta & t-statistic & Lower bound & Upper bound & Tolerance & VIF \\
\hline Constant & -1.69 & 39.67 & & -0.043 & -80.3 & 76.9 & & \\
\hline Sex $(0=$ females $; 1=$ males $)$ & 40.97 & 4.79 & 0.59 & $8.55^{*}$ & 31.5 & 50.5 & 0.52 & 1.91 \\
\hline $\mathrm{Age}^{2}$ & -0.013 & 0.002 & -0.27 & $-5.27^{*}$ & -0.018 & -0.008 & 0.93 & 1.07 \\
\hline Race $(0=$ black; $1=$ white & 12.44 & 3.54 & 0.18 & $3.52^{*}$ & 5.4 & 19.4 & 0.95 & 1.05 \\
\hline \multirow[t]{2}{*}{ Height $(\mathrm{cm})$} & 0.78 & 0.245 & 0.22 & $3.17^{*}$ & 0.3 & 1.3 & 0.52 & 1.92 \\
\hline & Sum of squares & Df & Mean square & $\mathrm{F}$ & Sig. & & & \\
\hline \multicolumn{9}{|l|}{ ANOVA results } \\
\hline Regression & 103,381 & 4 & 25,845 & 74 & 0.000 & & & \\
\hline Residual & 39,759 & 113 & 351.85 & & & & & \\
\hline Total & 143,139 & 117 & & & & & & \\
\hline
\end{tabular}

* $t$-statistic was statistically significant $(p<0.01)$; $\mathrm{SE}=$ standard error; Durbin-Watson Statistic $=1.92 ;$ Overall $\mathrm{R}^{2}=0.72 ;$ Standard error of the estimate $(\mathrm{SEE})=18.8 \mathrm{~mL} /$ $\mathrm{min} / \mathrm{mmHg}$. Sex, Age ${ }^{2}$, Race, and Height, accounted for approximately $60 \%, 6 \%, 5 \%$, and $3 \%$ of the total variance in the model. ANOVA results were rounded to the nearest whole number except for Residual Mean Square error, which was rounded to two decimal places

males) completed all tests. The subjects ranged from 18 to 67 years of age, and the mean resting heart rate was 80 (SD 10) beats/min. Two African American subjects (3\% of the black sample) were ex-smokers, with each having a previous exposure of two-pack years. One of the subjects that previously smoked quit 1.5 years before the start of the study, and the other subject quit 1 year before study commencement. The remining African American subjects were never smokers.

A white reference sample of exactly 32 females and 27 males used in the development of $\mathrm{DLNO}_{5 \mathrm{~s}}$ reference equations was randomly drawn from a population matched to the black sample for sex, age, and height. All these subjects were never smokers. The statistics program SPSS randomly sampled the white reference subjects from the dataset used elsewhere [27]. There were no differences in mean age or height between whites and blacks (Table 1). More detailed anthropometric characteristics of the black subjects are presented in Additional file 1: Table S3.

The mean FVC and $\mathrm{FEV}_{1}$ in the black subjects were statistically larger compared to the percent predicted for race, age, height and sex (Additional file 1: Table S4). However, interestingly, TLC was $\sim 100 \%$ predicted in the black subjects (Additional file 1: Table S4), which was a prediction equation created for white subjects.

Due to the likelihood of inadequate gas penetration in the lung with a $5 \mathrm{~s}$ breath-hold maneuver compared to a $10 \mathrm{~s}$ breath-hold maneuver, $\mathrm{DLCO}_{10 \mathrm{~s}}$ was compared to the $\mathrm{DLCO}_{5 \mathrm{~s}}$ in the black subjects. There was an $\sim 8 \%$ coefficient of variation between $\mathrm{DLCO}_{10 \mathrm{~s}}$ and $\mathrm{DLCO}_{5 \mathrm{~s}}$, but there was no mean difference between the two breathhold times $(p>0.8)$ (Additional file 1: Table S5, Figure S3).
About $80 \%$ of the variance $\mathrm{DLCO}_{10 \mathrm{~s}}$ was accounted for by $\mathrm{DLCO}_{5 \mathrm{~s}}$ (Additional file 1: Figure S1). Furthermore, there was a $6 \%$ coefficient of variation between $\mathrm{VA}_{10 \mathrm{~s}}$ and $\mathrm{VA}_{5 \mathrm{~s}}$, and $\mathrm{a}+0.15 \mathrm{~L}$ (SD 0.40) higher mean value (i.e., 3\% higher) with the $5 \mathrm{~s}$ breath-hold compared to the $10 \mathrm{~s}$ breath-hold maneuver in the black subjects $(p<0.01)$ (Additional file 1: Table S5, Figure S4). Approximately $88 \%$ of the variance in $\mathrm{VA}_{10 \text { s }}$ was shared by $\mathrm{VA}_{5 \mathrm{~s}}$ (Additional file 1: Figure S2). There was an $\sim 6 \%$ coefficient of variation between $\mathrm{KCO}_{10 \mathrm{~s}}$ and $\mathrm{KCO}_{5 \mathrm{~s}}$, with $\mathrm{KCO}_{10 \text { s }}$ showing a $0.16 \mathrm{~mL} / \mathrm{min} / \mathrm{mmHg} / \mathrm{L}$ larger value compared to $\mathrm{KCO}_{5 \mathrm{~s}}(\mathrm{p}<0.01$, Additional file 1: Figure S3 and S6). About $74 \%$ of the variance $\mathrm{KCO}_{10 \mathrm{~s}}$ was accounted for by $\mathrm{KCO}_{5 \mathrm{~s}}$ (Additional file 1: Figure S1).

The $\mathrm{DLNO}_{5 \mathrm{~s}}$ ranged from 71 to $205 \mathrm{~mL} / \mathrm{min} / \mathrm{mmHg}$ in the black subjects (Additional file 1: Table S6). The specific concentrations of inspired and expired gases as well as the actual breath-hold times are found in Additional file 1: Table S7. The $\mathrm{DLNO}_{5 \mathrm{~s}}$ was about $5 \times$ larger than the $\mathrm{DLCO}_{5 \mathrm{~s}}$ (Additional file 1: Table S6) with the regression equation being $\mathrm{DLNO}_{5 \mathrm{~s}}=4.65 \cdot\left(\mathrm{DLCO}_{5 \mathrm{~s}}\right)+10.94$, $\mathrm{R}^{2}=0.93, \mathrm{SEE}=9.2 \mathrm{~mL} / \mathrm{min} / \mathrm{mmHg}, p<0.01$. The $95 \%$ $\mathrm{CI}$ for the slope between $\mathrm{DLNO}_{5 \mathrm{~s}}$ and $\mathrm{DLCO}_{5 \mathrm{~s}}$ was 4.30-5.00.

Heart rate at rest was negatively associated with DLNO $_{5 \mathrm{~s}}$ and $\mathrm{DLCO}_{5 \mathrm{~s}}$ in the black subjects (Additional file 1: Figure S7). When the effects of age were partialled out, there was an 18-21\% shared variance between heart rate and diffusing capacity.

Multiple linear regression results are presented in Tables 2, 3 and 4. Approximately 72\% of the variance in $\mathrm{DLNO}_{5 \mathrm{~s}}$ was accounted for by sex $(\sim 60 \%)$, Age $(\sim 6 \%)$, Race $(\sim 5 \%)$, and Height (3\%) (Table 2$)$. Blacks 
Table 3 Multiple linear regression results for DLCO (5 s breath-hold)

\begin{tabular}{|c|c|c|c|c|c|c|c|c|}
\hline \multirow[t]{2}{*}{$N=118$} & \multicolumn{2}{|l|}{$\begin{array}{l}\text { Unstandardized } \\
\text { coefficients }\end{array}$} & \multicolumn{2}{|c|}{ Standardized coefficients } & \multicolumn{2}{|c|}{$\begin{array}{l}95 \% \text { Confidence interval for } \\
\text { beta }\end{array}$} & \multicolumn{2}{|l|}{$\begin{array}{l}\text { Collinearity } \\
\text { statistics }\end{array}$} \\
\hline & Beta & SE & Beta & t-statistic & Lower bound & Upper bound & Tolerance & VIF \\
\hline Constant & 2.02 & 7.93 & & 0.26 & -13.7 & 17.7 & & \\
\hline $\operatorname{Sex}(0=$ females $; 1=$ males $)$ & 8.40 & 0.96 & 0.60 & $8.77^{*}$ & 6.50 & 10.29 & 0.52 & 1.91 \\
\hline Race $(0=$ black; $1=$ white & 3.87 & 0.71 & 0.28 & $5.48^{*}$ & 2.5 & 5.3 & 0.95 & 1.05 \\
\hline $\mathrm{Age}^{2}$ & -0.002 & 0.00 & -0.23 & $-4.44^{*}$ & -0.003 & -0.001 & 0.93 & 1.07 \\
\hline \multirow[t]{2}{*}{ Height (cm) } & 0.14 & 0.049 & 0.19 & $2.78^{*}$ & 0.4 & 0.2 & 0.52 & 1.92 \\
\hline & Sum of squares & Df & Mean square & $F$ & Sig. & & & \\
\hline \multicolumn{9}{|l|}{ ANOVA results } \\
\hline Regression & 4209 & 4 & 1052 & 75 & 0.000 & & & \\
\hline Residual & 1587 & 113 & 14.05 & & & & & \\
\hline Total & 5796 & 117 & & & & & & \\
\hline
\end{tabular}

* $t$-statistic was statistically significant $(p<0.01)$; $\mathrm{SE}=$ standard error; Durbin-Watson Statistic $=2.08$; Overall $\mathrm{R}^{2}=0.73$; Standard error of the estimate $(\mathrm{SEE})=3.8 \mathrm{~mL} /$ $\mathrm{min} / \mathrm{mmHg}$. Sex, Race, Age ${ }^{2}$, and Height, accounted for approximately $57 \%, 10 \%, 4 \%$, and $2 \%$ of the total variance in the model. ANOVA results were rounded to the nearest whole number except for Residual Mean Square error, which was rounded to two decimal places

Table 4 Multiple linear regression results for alveolar volume (VA) (5 s breath-hold)

\begin{tabular}{|c|c|c|c|c|c|c|c|c|}
\hline \multirow[t]{2}{*}{$\mathrm{N}=118$} & \multicolumn{2}{|l|}{$\begin{array}{l}\text { Unstandardized } \\
\text { coefficients }\end{array}$} & \multicolumn{2}{|c|}{ Standardized coefficients } & \multicolumn{2}{|c|}{$95 \%$ Confidence interval for beta } & \multicolumn{2}{|l|}{$\begin{array}{l}\text { Collinearity } \\
\text { statistics }\end{array}$} \\
\hline & Beta & SE & Beta & $t$-statistic & Lower bound & Upper bound & Tolerance & VIF \\
\hline Constant & -6.16 & 1.41 & & $-4.36^{*}$ & -9.0 & -3.4 & & \\
\hline Height (cm) & 0.065 & 0.01 & 0.52 & $7.59^{*}$ & 0.05 & 0.08 & 0.55 & 1.83 \\
\hline $\operatorname{Sex}(0=$ females; $1=$ males $)$ & 0.835 & 0.17 & 0.34 & $5.02^{*}$ & 0.5 & 1.2 & 0.56 & 1.79 \\
\hline \multirow[t]{2}{*}{ Race $(0=$ black; $1=$ white } & 0.64 & 0.13 & 0.26 & $5.08^{*}$ & 0.39 & 0.90 & 0.96 & 1.04 \\
\hline & Sum of squares & Df & Mean square & $\mathbf{F}$ & Sig. & & & \\
\hline \multicolumn{9}{|l|}{ ANOVA results } \\
\hline Regression & 129 & 4 & 43 & 95 & 0.000 & & & \\
\hline Residual & 52 & 113 & 0.454 & & 0.000 & & & \\
\hline Total & 181 & 117 & & & & & & \\
\hline
\end{tabular}

${ }^{*} t$-statistic was statistically significant $(p<0.01)$; $\mathrm{SE}=$ standard error; Durbin-Watson Statistic $=2.38$; Overall $\mathrm{R}^{2}=0.71 ; \mathrm{Standard}$ error of the estimate $(\mathrm{SEE})=0.67 \mathrm{~L}$. Height, Sex, and Race accounted for approximately $60 \%, 6 \%$, and $5 \%$ of the total variance in the model. ANOVA results were rounded to the nearest whole number except for Residual Mean Square error, which was rounded to two decimal places

had a 12.4 (95\% CI 5.4-19.4) $\mathrm{mL} / \mathrm{min} / \mathrm{mmHg}$ lower $\mathrm{DLNO}_{5 \mathrm{~s}}$ compared to whites after controlling for sex, age, and height. Approximately $73 \%$ of the variance in DLCO $_{5 \mathrm{~s}}$ was accounted for by sex $(\sim 57 \%)$, race $(10 \%)$, age $(\sim 4 \%)$, and height $(2 \%)$ (Table 3$)$. Blacks had a $3.9\left(95 \%\right.$ CI 2.5-5.3) $\mathrm{mL} / \mathrm{min} / \mathrm{mmHg}$ lower $\mathrm{DLCO}_{5 \mathrm{~s}}$ compared to whites after controlling for sex, age, and height. Approximately $71 \%$ of the variance in $\mathrm{VA}_{5 \mathrm{~s}}$ was accounted for by height $(\sim 60 \%)$, sex $(\sim 6 \%)$, and race (5\%) (Table 4). Blacks had a 0.6 L (95\% CI 0.4-0.9) L lower $\mathrm{VA}_{5 \mathrm{~s}}$ compared to whites after controlling for sex, age, and height.

To confirm that there is a racial difference in $\mathrm{DLNO}_{5 \mathrm{~s}}$ and to demonstrate that the results are like Table 2, we performed other analyses post-hoc. We decided to randomly sample a new set of 59 Caucasian subjects from the 2017 ERS Taskforce with similar heights and ages, and sex compared to the 59 African American subjects [27]. In this instance, approximately $66 \%$ of the variance in $\mathrm{DLNO}_{5 \mathrm{~s}}$ was accounted for by sex $(\sim 51 \%)$, race $(\sim 9 \%)$, Age $^{2}(\sim 5 \%)$, Race ( 9\%), and Height (2\%). This does suggest that race is an independent predictor of $\mathrm{DLNO}_{5 \mathrm{~s}}$ between these age ranges.

\section{Discussion}

This observational descriptive study 's main purpose was to evaluate racial differences in pulmonary diffusing capacity between black and white populations. As 
this was a pilot study, we collected data on $\sim 60$ young, healthy black adults and used those data to compare against a reference set of healthy white adults [27].

Our result demonstrates a small but important and significant racial difference in $\mathrm{DLNO}_{5 \mathrm{~s}}, \mathrm{DLCO}_{5 \mathrm{~s}}$, and $\mathrm{VA}_{5 s}$. Approximately $5-10 \%$ of the total shared variance was accounted for by race in these main dependent variables. Interestingly, race was not a significant predictor for $\mathrm{KNO}_{5 \mathrm{~s}}$ and $\mathrm{KCO}_{5 \mathrm{~s}}$ (which is mathematically $\mathrm{DLNO}_{5 \mathrm{~s}} /$ $\mathrm{VA}_{5 \mathrm{~s}}$ and $\mathrm{DLCO}_{5 \mathrm{~s}} / \mathrm{VA}_{5 \mathrm{~s}}$ ). This suggests that the lower $\mathrm{VA}_{5 \mathrm{~s}}$ in blacks contributed to differences in $\mathrm{DLNO}_{5 \mathrm{~s}}$ and $\mathrm{DLCO}_{5 s}$. Total lung capacity was nearly $100 \%$ of predicted in the black population when prediction equations were applied for a white population [3], suggesting that there was additional dead space ventilation and/or increased residual volume in the black subjects.

A secondary aim was to compare differences in DLCO, $\mathrm{VA}$ and $\mathrm{KCO}$ in the black population at $10 \mathrm{~s}$ versus $5 \mathrm{~s}$ breath-holds. The DLCO was similar between both breath-hold times, however, VA was lower by about $150 \mathrm{~mL}$ when the $10 \mathrm{~s}$ breath-hold maneuver was performed (Additional file 1: Figures S4-S5). As such, $\mathrm{KCO}$ was about $0.16 \mathrm{~mL} / \mathrm{min} / \mathrm{mmHg}$ larger at $10 \mathrm{~s}$ vs $5 \mathrm{~s}$ breath-hold time. Similarly, Moinard and Guénard also demonstrated that VA was lower and $\mathrm{KCO}$ was larger at the longer breath-hold time in healthy subjects [62]. However, in their paper, these changes were nonsignificant due to the small sample size. Other studies show varying changes on DLCO, VA, and KCO at various breath-hold times in healthy subjects [39, 46, 63]. The conflicting data on varied breath-hold times affecting these parameters can be due to the heterogeneous ventilation distribution, or heterogeneous inspired gas penetration, between subjects in these studies. Independence of breath-hold time implies homogeneous distribution of KCO [64], and based on varied results between studies, some subjects demonstrated more heterogeneous ventilation distribution compared to other subjects, even though all subjects in these studies were classified as healthy $[39,46,63]$.

Limited data exists on racial differences in DLNO. One previous study demonstrated that in sex, age, and height matched in white subjects, DLNO and DLCO were $\sim 23, \sim 5 \mathrm{~mL} / \mathrm{min} / \mathrm{mmHg}$ higher, and VA was $\sim 1$ $\mathrm{L}$ more compared to African subjects [45]. That difference is higher compared to the $0.15 \mathrm{~L}$ difference identified in this study. Previous studies have also revealed that vital capacity was $\sim 15 \%$ lower in blacks compared to age, height, and sex-matched whites [13, 43], and the DLCO was also lower in blacks compared to matched whites $[13,19]$. Specifically, DLCO is lower by $\sim 2(\sim 6 \%)$ $\mathrm{mL} / \mathrm{min} / \mathrm{mmHg}$ in black, age and height matched males compared with matched white males, and $\sim 5(\sim 15 \%)$
$\mathrm{mL} / \mathrm{min} / \mathrm{mmHg}$ lower in black, age and height matched females compared to matched white females, respectively [19]. Thus, the difference in DLCO between blacks and whites stemmed from differences in VA and hemoglobin concentration as there was a $\sim 6 \%$ larger hemoglobin concentration in whites compared to blacks [19].

This study revealed, when matched for age and height, DLNO is $\sim 8 \%$ lower in African American males and $10 \%$ lower in African American females compared to whites. If $2.5 \%$ of this population is considered to have abnormally low DLNO, ${ }^{1}$ then approximately 862,000 African Americans $\geq 18$ years of age in the United States could theoretically have lung disease. ${ }^{2}$ If a prediction equation created for the white population was applied to blacks, lung disease would be over diagnosed by approximately $8 \%$, with significant implications for approximately 2.65 million individuals. This false positive misdiagnosis could increase patient stress and the inadvertent use of healthcare resources could result in a higher cost for a non-illness. Currently, there is no evidence that having a high DLNO is considered a pathologic state; thus underestimating the upper limit of normal for a black population when using a prediction equation for whites has no real consequence.

On the other hand, having a large DLCO, in certain cases, can suggest a pathological state. For example, those who are diagnosed with Goodpasture's Syndrome [65], or who are obese [66], polycythemic [67], or those with a pulmonary hemorrhage [68], can have an abnormally high DLCO. Thus, depending on the prevalence of each of these conditions in the black population, applying the wrong reference equation can result in additional harm. The consequences of providing a false negative to a patient for DLCO could significantly further impact the overall cost of healthcare, as well as negatively impact survival, and provide false reassurance. [69]. A falsenegative result is a missed opportunity, and may require more aggressive treatment down the line with potential medical legal consequences as well. [69].

What about comparing the false-negative rate using the traditional DLCO test with that of the relatively new DLNO test irrespective of race? Recent data has demonstrated that the false-negative rate for diagnosing various cardiopulmonary diseases after measuring DLNO was $10 \%$, but for DLCO, it was $16 \%$ [26]. Thus, there was a $6 \%$ lower false-negative rate when using DLNO as a diagnostic test compared to DLCO.

\footnotetext{
${ }^{1}$ A z-score of -1.96 SD units (2.5th percentile) is considered the LLN for case finding purposes of asymptomatic subjects based on a standard Gaussian distribution (Eur Respir J. 2012;40(6):1324-43).

2 As of 2021, there are about 34,506,788 African Americans in the U.S $\geq 18$ years of age.
} 
Our study benefited from the technical quality of the PFTs, further supporting our conclusions (Additional file 1: Tables S4, S5, S7). Mean inspired volumes were $94 \%$ of the FVC during the $\mathrm{DLCO}_{10 \mathrm{~s}}$ and $89 \%$ of the FVC for the $\mathrm{DLNO}_{5 \mathrm{~s}}$ test. Breath-hold time varied between 8 and $12 \mathrm{~s}$ for the $10 \mathrm{~s}$ breath hold test and $4-6 \mathrm{~s}$ for the $5 \mathrm{~s}$ breath-hold test. The mean $\mathrm{VA}_{5 \mathrm{~s}}$ and $\mathrm{VA}_{10 \mathrm{~s}}$ was $91 \%$ and $88 \%$ of the measured TLC from the body plethysmograph, respectively.

There are a few caveats to consider. First, data shows that fitness may impact $\mathrm{DLNO}_{5 \mathrm{~s}}$ and $\mathrm{DLCO}_{5 \mathrm{~s}}[70,71]$. Although this may be true; however, the Global Lung Function Initiative (GLI) equations for pulmonary diffusing capacity (the gold standard) also do not account for fitness [8]. Fitness may also be a factor in racial differences of DLNO. However, this does not negate the need for racially appropriate reference equations. It would not be feasible to measure aerobic capacity in every patient prior to a pulmonary function test. Despite this suggestion, it has been shown that the mean difference in aerobic capacity between blacks and whites is $2.5 \mathrm{~mL} /$ $\mathrm{kg} / \mathrm{min}$ [72], which is too small to cause a difference in pulmonary diffusing capacity. For example, every $1 \mathrm{~mL} /$ $\mathrm{kg} / \mathrm{min}$ increase in aerobic capacity, $\mathrm{DLNO}_{5 \mathrm{~s}}$ increases by about $1 \mathrm{~mL} / \mathrm{min} / \mathrm{mmHg}$ [70]. Thus, a $\sim 2.5 \mathrm{~mL} / \mathrm{kg} / \mathrm{min}$ lower aerobic capacity in blacks should result in a $\sim 2.5$ and not a $12 \mathrm{~mL} / \mathrm{min} / \mathrm{mmHg}$ lower $\mathrm{DLNO}_{5 \mathrm{~s}}$ in blacks, as we demonstrated. Another caveat to consider is that we used a fixed hemoglobin concentration as it was not measured. However, we believe that this does not diminish our findings. First, in major hospital labs, measuring hemoglobin concentration prior to every pulmonary function test is not practical. Second, the Global Lung Function Initiative reference equations for $\mathrm{DLCO}_{10 \mathrm{~s}}$ do not adjust for hemoglobin concentration [8] (see explanation on the bottom of page 8 and the top of page nine in ERS technical standards of why this is not necessary to correct for $\mathrm{Hb}$ [8]). In essence, correcting for hemoglobin does not improve overall model fit [8]. Third, in our previous work, we also demonstrate minimal differences in DLCO when using corrected vs. non-corrected hemoglobin values [30]. Fourth, DLNO is minimally affected by Hb [29]. Thus, DLCO and DLNO hemoglobin correction is not needed. Finally, a recent article published in 2021 demonstrates that the Hyp'Air pulmonary function device measures DLNO that may be about $17 \%$ higher than that of the Masterscreen PFT Pro equipment (Carefusion, USA) [73]). These between machine differences could confound the findings of this study. However, the between machine differences are unlikely to affect the current findings since the reference equations published in the ERS technical standards [27] are mostly from subjects that had DLNO assessed by the Hyp'Air device, which is the same device used in this study. We did not use the Masterscreen PFT system for the measurement of DLNO.

\section{Conclusion}

In conclusion, the results of this pilot data reveal small but important and statistically significant racial differences in DLNO and DLCO in adults, which are due, in part, to differences in VA. Future reference equations should account for racial differences. If these differences are not accounted for, then the risk of falsely diagnosing lung disease increase in blacks when using reference equations for whites.

\begin{abstract}
Abbreviations
ATS: American Thoracic Society; CO: Carbon monoxide; $\mathrm{COHb}$ : Carboxyhemoglobin; COPD: Chronic obstructive pulmonary disease; DL: Diffusing capacity of the lung; DLCO: Diffusing capacity of the lung for carbon monoxide ( $\mathrm{mL} /$ $\mathrm{min} / \mathrm{mmHg})$; DLNO: Diffusing capacity of the lung for nitric oxide $(\mathrm{mL} / \mathrm{min} /$ $\mathrm{mmHg}$ ); DMCO: Alveolar-capillary membrane diffusing capacity for CO; ERS: European Respiratory Society; FEV 1 : Forced expiratory volume in $1 \mathrm{~s}$; FVC: Forced vital capacity; FRC: Functional residual capacity; GSU: Georgia State University; Hb: Hemoglobin; KCO: Logarithmic change in CO concentration per unit time and unit pressure $(\mathrm{mL} \mathrm{STPD} / \mathrm{min} / \mathrm{mmHg} / \mathrm{L})$ and mathematically equivalent to DLCO divided by alveolar volume; NO: Nitric oxide; KNO: Logarithmic change in NO concentration per unit time and unit pressure $\mathrm{mL}(\mathrm{STPD} / \mathrm{min} / \mathrm{mmHg} / \mathrm{L}$ ) and mathematically equivalent to DLNO divided by alveolar volume; LLN: Lower limit of normal, taken as the 2.5th percentile; PFTs: Pulmonary function tests; VA: Alveolar volume (L); Vc: Pulmonary capillary blood volume (mL); TLC: Total lung capacity (L); ULN: Upper limit of normal, taken as the 97.5 th percentile.
\end{abstract}

\section{Supplementary Information}

The online version contains supplementary material available at https://doi. org/10.1186/s12890-021-01591-7.

Additional file 1. Supplementary figures and tables.

\section{Acknowledgements}

This manuscript originated from the Master's Thesis of Ahmad Almamary in 2017, titled "Prediction equations for pulmonary diffusing capacity for nitric oxide in African American Adults": https://scholarworks.gsu.edu/rt_theses/40/.

\section{Author's information}

GSZ obtained his Ph.D. in 2001 from the University of British Columbia focusing on pulmonary diffusion limitations during high intensity exercise. He holds a license to practice respiratory care in the state of California. In addition, he is on the editorial boards for the journals Respiratory Physiology and Neurobiology, and Medicine and Science in Sports and Exercise. GSZ was the co-chair of the European Respiratory Society Task Force on the standardization of DLNO, which was published in the European Respiratory Journal in 2017. As well, because of these technical standards, he was a guest editor for the complete July 2017 issue of Respiratory Physiology and Neurobiology (Volume 241, pages 1-72) which was specifically dedicated to articles on DLNO. GSZ can be reached at gerryzavorsky@gmail.com or gszavorsky@ucdavis.edu.

\section{Authors' contributions}

A literature search was performed by ASA and GSZ. Data collection was performed by ASA MKA, and GSZ. Data analysis was performed by GSZ. The study design was determined by GSZ. Manuscript preparation was performed by GSZ, SHSS, and DSG. Those responsible for drafting the work and revising it 
critically were GSZ, ASA, MKA, SHSS, and DSG. All authors read and approved the final manuscript.

\section{Funding}

Jerome M. Sullivan Research Fund from the American Respiratory Care Foundation (ARCF). The role of the funding body was to solely provide funding for the study.

\section{Availability of data and materials}

The datasets used and/or analyzed during the current study are available from the corresponding author [GSZ] on reasonable request.

\section{Declarations}

\section{Ethics approval and consent to participate}

This study received ethics approval from the Georgia State University ethics board (IRB \#H16120, Reference \# 335588). This research has been performed in accordance with the declaration of Helsinki. Informed consent was obtained from all African American subjects.

\section{Consent for publication}

Not applicable.

\section{Competing interests}

The authors declare that they have no competing interests.

\section{Author details}

${ }^{1}$ Pulmonary Services Department, University of California, Davis, Medical Center, 2315 Stockton Boulevard, Room 5703, Sacramento, CA 95817, USA. ${ }^{2}$ Faculty of Medicine, National Heart and Lung Institute, Imperial College London, London, UK. ${ }^{3}$ Institute of Cardiovascular Sciences, University of Birmingham, Birmingham, UK. ${ }^{4}$ Department of Respiratory Therapy, Georgia State University, Atlanta, GA, USA.

Received: 2 March 2021 Accepted: 31 May 2021

Published online: 13 July 2021

\section{References}

1. Ogilvie CM, Forster RE, Blakemore WS, Morton JW. A standardized breath holding technique for the clinical measurement of the diffusing capacity of the lung for carbon monoxide. J Clin Invest. 1957;36(1 Part 1):1-17.

2. Gutierrez C, Ghezzo RH, Abboud RT, Cosio MG, Dill JR, Martin RR, et al. Reference values of pulmonary function tests for Canadian Caucasians. Can Respir J. 2004:11(6):414-24.

3. Verbanck S, Van Muylem A, Schuermans D, Bautmans I, Thompson B, Vincken W. Transfer factor, lung volumes, resistance and ventilation distribution in healthy adults. Eur Respir J. 2016;47(1):166-76.

4. Garcia-Rio F, Dorgham A, Galera R, Casitas R, Martinez E, Alvarez-Sala R, et al. Prediction equations for single-breath diffusing capacity in subjects aged 65 to 85 years. Chest. 2012;142(1):175-84.

5. Thompson BR, Johns DP, Bailey M, Raven J, Walters EH, Abramson MJ. Prediction equations for single breath diffusing capacity (TICO) in a middle aged caucasian population. Thorax. 2008;63(10):889-93.

6. Crapo RO, Morris AH. Standardized single breath normal values for carbon monoxide diffusing capacity. Am Rev Respir Dis. 1981;123(2):185-9.

7. Knudson RJ, Kaltenborn WT, Knudson DE, Burrows B. The single-breath carbon monoxide diffusing capacity. Reference equations derived from a healthy nonsmoking population and effects of hematocrit. Am Rev Respir Dis. 1987;135(4):805-11.

8. Stanojevic S, Graham BL, Cooper BG, Thompson BR, Carter KW, Francis RW, et al. Official ERS technical standards: global lung function initiative reference values for the carbon monoxide transfer factor for Caucasians. Eur Respir J. 2017;50(3):1700010.

9. Kim YJ, Christoph K, Yu Z, Eigen H, Tepper RS. Pulmonary diffusing capacity in healthy African-American and Caucasian children. Pediatr Pulmonol. 2016:51(1):84-8.

10. Chhabra SK, Kumar R, Mittal V. Prediction equations for spirometry for children from Northern India. Indian Pediatr. 2016;53(9):781-5.
11. Gochicoa-Rangel L, Del-Rio-Hidalgo R, Alvarez-Arroyo MR, MartinezBriseno D, Mora-Romero U, Martinez-Valdeavellano L, et al. Diffusing capacity of the lung for carbon monoxide in Mexican/Latino children. Quality control and reference values. Ann Am Thorac Soc. 2019;16(2):240-7.

12. Amra B, Asadi M, Salehi H, Zamani AR, Golshan M. Normative reference values for lung transfer factor in Isfahan. Iran Respirology. 2006;11(4):477-81.

13. Pesola GR, Sunmonu Y, Huggins G, Ford JG. Measured diffusion capacity versus prediction equation estimates in blacks without lung disease. Respiration. 2004;71(5):484-92.

14. Neder JA, Andreoni S, Peres C, Nery LE. Reference values for lung function tests. III. Carbon monoxide diffusing capacity (transfer factor). Braz J Med Biol Res. 1999;32(6):729-37.

15. Chhabra SK, Kumar R, Gupta UA. Prediction equations for diffusing capacity (transfer factor) of lung for North Indians. Lung India. 2016;33(5):479-86.

16. Yang SC, Yang SP, Lin PJ. Prediction equations for single-breath carbon monoxide diffusing capacity from a Chinese population. Am Rev Respir Dis. 1993;147(3):599-606.

17. Roca J, Rodriguez-Roisin R, Cobo E, Burgos F, Perez J, Clausen JL. Singlebreath carbon monoxide diffusing capacity prediction equations from a Mediterranean population. Am Rev Respir Dis. 1990;141(4 Pt 1):1026-32.

18. Ip MS, Lam WK, Lai AY, Ko FW, Lau AC, Ling SO, et al. Reference values of diffusing capacity of non-smoking Chinese in Hong Kong. Respirology. 2007;12(4):599-606.

19. Neas LM, Schwartz J. The determinants of pulmonary diffusing capacity in a national sample of U.S. adults. Am J Respir Crit Care Med. 1996;153(2):656-64.

20. Vazquez-Garcia JC, Perez-Padilla R, Casas A, Schonffeldt-Guerrero P, Pereira J, Vargas-Dominguez $C$, et al. Reference values for the diffusing capacity determined by the single-breath technique at different altitudes: The Latin American single-breath diffusing capacity reference project. Respir Care. 2016;61(9):1217-23.

21. Borland $C$, Guenard $H$. The history of the pulmonary diffusing capacity for nitric oxide DL. NO Respir Physiol Neurobiol. 2017;241:3-6.

22. Borland C, Cracknell N, Higenbottam T. Is the measurement of "DLNO" a true measure of membrane diffusing capacity? Clin Sci (Lond). 1984;67(S9):41P.

23. Borland C, Chamberlain A, Higenbottam T. The fate of inhaled nitric oxide [abstract]. Clin Sci (Lond). 1983;65(3):37P.

24. Guénard H, Varene N, Vaida P. Determination of lung capillary blood volume and membrane diffusing capacity in man by the measurements of NO and CO transfer. Respir Physiol. 1987;70(1):113-20.

25. Borland CD, Higenbottam TW. A simultaneous single breath measurement of pulmonary diffusing capacity with nitric oxide and carbon monoxide. Eur Respir J. 1989;2(1):56-63.

26. Zavorsky GS, van der Lee I. Can the measurement of pulmonary diffusing capacity for nitric oxide replace the measurement of pulmonary diffusing capacity for carbon monoxide? Respir Physiol Neurobiol. 2017;241:9-16.

27. Zavorsky GS, Hsia CC, Hughes JM, Borland CD, Guenard H, van der Lee I, et al. Standardisation and application of the single-breath determination of nitric oxide uptake in the lung. Eur Respir J. 2017:49(2):1600962.

28. Borland CD, Dunningham H, Bottrill F, Vuylsteke A, Yilmaz C, Dane DM, et al. Significant blood resistance to nitric oxide transfer in the lung. J Appl Physiol. 2010;108(5):1052-60.

29. van der Lee I, Zanen P, Biesma DH, van den Bosch JM. The effect of red cell transfusion on nitric oxide diffusing capacity. Respiration. 2005;72(5):512-6.

30. Zavorsky GS. The rise in carboxyhemoglobin from repeated pulmonary diffusing capacity tests. Respir Physiol Neurobiol. 2013;186(1):103-8.

31. Borland CD, Cox Y. Effect of varying alveolar oxygen partial pressure on diffusing capacity for nitric oxide and carbon monoxide, membrane diffusing capacity and lung capillary blood volume. Clin Sci (Lond). 1991;81(6):759-65.

32. Guenard HJ, Martinot JB, Martin S, Maury B, Lalande S, Kays C. In vivo estimates of $\mathrm{NO}$ and $\mathrm{CO}$ conductance for haemoglobin and for lung transfer in humans. Respir Physiol Neurobiol. 2016;228:1-8.

33. Dressel $H$, Filser $L$, Fischer R, Marten K, Muller-Lisse U, de la Motte D, et al. Lung diffusing capacity for nitric oxide and carbon monoxide in relation 
to morphological changes as assessed by computed tomography in patients with cystic fibrosis. BMC Pulm Med. 2009;9(30):1-7.

34. Zavorsky GS, Cao J, Murias JM. Reference values of pulmonary diffusing capacity for nitric oxide in an adult population. Nitric Oxide. 2008;18(1):70-9.

35. van der Lee I, Zanen P, Stigter N, van den Bosch JM, Lammers JW. Diffusing capacity for nitric oxide: reference values and dependence on alveolar volume. Respir Med. 2007;101(7):1579-84.

36. Aguilaniu B, Maitre J, Glenet S, Gegout-Petit A, Guenard H. European reference equations for $\mathrm{CO}$ and $\mathrm{NO}$ lung transfer. Eur Respir J. 2008;31(5):1091-7.

37. Rouatbi S, Ben Saad H, Latiri I, Tabka Z, Guenard H. North-African reference values of alveolar membrane diffusion capacity and pulmonary capillary blood volume. Respiration. 2010;80(4):301-12.

38. Munkholm M, Marott JL, Bjerre-Kristensen L, Madsen F, Pedersen OF, Lange $P$, et al. Reference equations for pulmonary diffusing capacity of carbon monoxide and nitric oxide in adult Caucasians. Eur Respir J. 2018;52(1):1500677. https://doi.org/10.1183/13993003.00677-2015.

39. Thomas A, Hanel B, Marott JL, Buchvald F, Mortensen J, Nielsen KG. The single-breath diffusing capacity of $\mathrm{CO}$ and $\mathrm{NO}$ in healthy children of European descent. PLOS ONE. 2014;9(12):e113177.

40. Rouatbi S, Khemis M, Garrouche A, Saad HB. Reference values of capillary blood volume and pulmonary membrane diffusing capacity in North African boys aged 8 to 16 years. Egypt J Chest Dis Tuberc. 2014;63(3):705-15.

41. Dridi R, Dridi N, Ben Moussa Zouita A, Muller PT, Tabka Z, Guenard H, et al. Pulmonary diffusing capacity measured by $\mathrm{NO} / \mathrm{CO}$ transfer in Tunisian boys. Pediatr Pulmonol. 2020;55(10):2754-61.

42. Kiefer EM, Hankinson JL, Barr RG. Similar relation of age and height to lung function among Whites, African Americans, and Hispanics. Am J Epidemiol. 2011;173(4):376-87.

43. Quanjer PH, Stanojevic S, Cole TJ, Baur X, Hall GL, Culver BH, et al. Multiethnic reference values for spirometry for the 3-95-yr age range: the global lung function 2012 equations. Eur Respir J. 2012;40(6):1324-43.

44. Cresanta JL, Croft JB, Webber LS, Nicklas TA, Berenson GS. Racial difference in hemoglobin concentration of young adults. Prev Med. 1987;16(5):659-69.

45. Simaga B, Forton K, Motoji Y, Naeije R, Faoro V. Lung diffusing capacity in sub-Saharan Africans versus European Caucasians. Respir Physiol Neurobiol. 2017;241:23-7.

46. Dressel H, Filser L, Fischer R, de la Motte D, Steinhaeusser W, Huber RM, et al. Lung diffusing capacity for nitric oxide and carbon monoxide: dependence on breath-hold time. Chest. 2008;133(5):1149-54.

47. Pre-exercise Evaluation. Chapter 2. Pages 27-57. In: ACSM's guidelines for exercise testing and prescription, 11 th edition. Philadelphia, PA: Wolters Kluwer. 2022. Senior Editor: Liguori G. Associate Editors: Feito Y, Fountaine C, Roy BA.

48. Miller MR, Crapo R, Hankinson J, Brusasco V, Burgos F, Casaburi R, et al. General considerations for lung function testing. Eur Respir J. 2005;26(1):153-61.

49. Miller MR, Hankinson J, Brusasco V, Burgos F, Casaburi R, Coates A, et al. Standardisation of spirometry. Eur Respir J. 2005;26(2):319-38.

50. Macintyre N, Crapo RO, Viegi G, Johnson DC, van der Grinten CP, Brusasco $\mathrm{V}$, et al. Standardisation of the single-breath determination of carbon monoxide uptake in the lung. Eur Respir J. 2005;26(4):720-35.

51. Wanger J, Clausen JL, Coates A, Pedersen OF, Brusasco V, Burgos F, et al. Standardisation of the measurement of lung volumes. Eur Respir $J$. 2005;26(3):511-22.

52. Zavorsky GS, Blood AB, Power GG, Longo LD, Artal R, Vlastos EJ. CO and NO pulmonary diffusing capacity during pregnancy: safety and diagnostic potential. Respir Physiol Neurobiol. 2010;170(3):215-25.
53. Graham BL, Brusasco V, Burgos F, Cooper BG, Jensen R, Kendrick A, et al. 2017 ERS/ATS standards for single-breath carbon monoxide uptake in the lung. Eur Respir J. 2017;49(1):1600016.

54. Thomas JR, Nelson JK, Silverman SJ. Relationships among variables. Research methods in physical activity. 7th ed. Champaign, IL: Human Kinetics; 2015. p. 133-54.

55. Mertler CA, Vannatta RA. Advanced and multivariate statistical methods. Practical application and interpretation. 5th ed. Los Angeles: Pyrczak Publishing; 2013. p. 361.

56. Mansfield ER, Helms BP. Detecting multicollinearity. Am Stat. 1982;36(3):158-60.

57. Kim JH. Multicollinearity and misleading statistical results. Korean J Anesthesiol. 2019;72(6):558-69.

58. Durbin J, Watson GS. Testing for serial correlation in least squares regression. 2. Biometrika. 1951;38(1-2):159-78.

59. Savin NE, White KJ. Durbin-Watson test for serial-correlation with extreme sample sizes or many regressors. Econometrica. 1977;45(8):1989-96.

60. Field A. Discovering statistics using IBM SPSS statistics. 4th ed. Thousand Oaks, CA: Sage Publications Ltd.; 2014.

61. Altman DG, Bland JM. Measurement in medicine-the analysis of method comparison studies. J R Stat Soc D-Stat. 1983;32(3):307-17.

62. Moinard J, Guénard H. Determination of lung capillary blood volume and membrane diffusing capacity in patients with COLD using the NO-CO method. Eur Respir J. 1990;3(3):318-22.

63. Turcotte RA, Perrault $\mathrm{H}$, Marcotte JE, Beland M. A test for the measurement of pulmonary diffusion capacity during high-intensity exercise. J Sports Sci. 1992;10(3):229-35.

64. Piiper J, Sikand RS. Determination of D-CO by the single breath method in inhomogeneous lungs: theory. Respir Physiol. 1966;1 (1):75-87.

65. Ewan PW, Jones HA, Rhodes CG, Hughes JM. Detection of intrapulmonary hemorrhage with carbon monoxide uptake. Application in goodpasture's syndrome. N Engl J Med. 1976;295(25):1391-6.

66. Saydain G, Beck KC, Decker PA, Cowl CT, Scanlon PD. Clinical significance of elevated diffusing capacity. Chest. 2004;125(2):446-52.

67. Riepl G. Effects of abnormal hemoglobin concentration in human blood on membrane diffusing capacity of the lung and on pulmonary capillary blood volume. Respiration. 1978;36(1):10-8.

68. DeCato TW, Hegewald MJ. Breathing red: physiology of an elevated single-breath diffusing capacity of carbon monoxide. Ann Am Thorac Soc. 2016;13(11):2087-92.

69. Petticrew M, Sowden A, Lister-Sharp D. False-negative results in screening programs. Medical, psychological, and other implications. Int J Technol Assess Health Care. 2001;17(2):164-70.

70. Zavorsky GS, Smoliga JM. The association between cardiorespiratory fitness and pulmonary diffusing capacity. Respir Physiol Neurobiol. 2017;241:28-35.

71. Lavin KM, Straub AM, Uhranowsky KA, Smoliga JM, Zavorsky GS. Alveolarmembrane diffusing capacity limits performance in Boston marathon qualifiers. PLOS ONE. 2012;7(9):e44513.

72. Kokkinos P, Myers J, Kokkinos JP, Pittaras A, Narayan P, Manolis A, et al. Exercise capacity and mortality in black and white men. Circulation. 2008; 117(5):614-22.

73. Radtke T, de Groot Q, Haile SR, Maggi M, Hsia CCW, Dressel H. Lung diffusing capacity for nitric oxide measured by two commercial devices: a randomized crossover comparison in healthy adults. ERJ Open Res. 2021. https://doi.org/10.1183/23120541.00193-2021.

\section{Publisher's Note}

Springer Nature remains neutral with regard to jurisdictional claims in published maps and institutional affiliations. 